\title{
Pulsión de muerte: una lectura desde el contexto carcelario*
}

\section{Pulsion of death: A reading from the prison context}

\author{
Víctor Hugo Rosero Arcos \\ Ferney Mora Acosta \\ Luis Carlos Rosero García** \\ Andrés Felipe Martínez Patiño \\ Universidad Mariana, Colombia
}

Recibido: 17 de agosto de 2017 Revisado: 16 de noviembre de 2017

Aceptado: 26 de enero de 2018

\section{Resumen}

El presente artículo es resultado de la investigación "Pulsión de muerte y actos delictivos en un grupo de internos del INPEC - Pasto". El objetivo de la investigación fue comprender la pulsión de muerte en los actos violentos presentes en un grupo de internos de la Cárcel Judicial de Pasto, que permitiera el diseño de una propuesta de intervención con la población seleccionada. Se realizó la reflexión de tres categorías: acontecimientos, la repetición y la rectificación subjetiva; desde un paradigma cualitativo, con enfoque hermenéutico y método etnográfico acudiendo como instrumentos de recolección: entrevista semi-estructurada, historia de vida y grupo focal. El estudio permite afirmar que, a pesar que en la mayoría de internos, no se presentan niveles altos de conducta antisocial, los porcentajes de internos

Artículo de investigación. La investigación contó con el apoyo de la Universidad Mariana, quien se encargó de la financiación en su totalidad. De igual manera, se reconoce el apoyo del INPEC - Pasto, que a través de sus directivas facilitó el proceso de recolección de información. Este trabajo es el resultado de la investigación titulada: "Pulsión de muerte y actos delictivos en un grupo de internos del INPEC - Pasto". Código del Proyecto: PS1-15 Acuerdo 004 de 28 de enero de 2015. Financiación total a cargo de la Universidad Mariana: 24.395.268, Fecha de inicio: noviembre de 2013 y Fecha de finalización: febrero de 2017. DOI: https://doi.org/10.15332/s1794-9998.2018.0002.07

Correspondencia: Luis Carlos Rosero García. Profesor del programa de Psicología, Facultad de Humanidades Cencias Sociales, Universidad Mariana, Pasto, Colombia. Correo electrónico: Irosero@umariana.edu.co 
que si presentan estos niveles no deben ser despreciados, puesto que esto implica una tendencia a la comisión de estas conductas durante su ciclo vital.

Palabras claves: Pulsión de muerte. Acontecimientos. Repetición. Rectificación subjetiva. Homicidio.

\section{Abstract}

This paper is the result of the research "Death drive and criminal acts in a group of inmates of INPEC - Pasto", completed in 2017, with the collaboration of the Mariana University and the inmates and officials of the National Penitentiary Institute and INPEC Prison - Pasto. The investigation was guided by the general objective of understanding the death drive in violent acts of a group of inmates of the Pasto Prison, which allowed for the design of an intervention proposal with the selected population. The specific objectives of the study were directed towards exhaustive reflection on three important categories: events, the unconscious mechanism of repetition and the process of subjective rectification; from a qualitative paradigm, with a hermeneutical approach and an ethnographic method as collecting instruments: the semi-structured interview, the life history, and the focus group. The study allows to affirm that, although in most inmates there are no high levels of antisocial behavior, the percentages of inmates who do present these levels should not be disregarded, since this implies a tendency to commit these behaviors during its life cycle.

Keywords: reflex, Death drive. Events. Repetition. Subjective rectification. Homicide.

\section{Introducción}

El presente artículo, resultado de la investigación sobre "Pulsión de muerte y actos delictivos" en el contexto penitenciario y carcelario (2017), posibilita situarse en el escenario de los testimonios y vivencias de un grupo de internos del INPEC (Instituto Nacional Penitenciario y Carcelario de Colombia)-Pasto quienes han cometido el delito de homicidio y permitió el desarrollo de una propuesta de intervención denominada "Rectificación subjetiva: Compromiso con la No-Repetición y acontecimiento".

Una de las preocupaciones que interesa a los investigadores sociales tiene que ver con la pulsión de muerte y su incidencia directa de los actos delictivos cometidos por estos sujetos. Por tanto, cabe mencionar que la vida adulta de los internos representa el escenario vital donde las pulsiones tienen un empuje de gran intensidad, ya que trae los reflejos de lo ocurrido en la adolescencia y la juventud, tal y como lo expresa Vadura (2016) en su artículo, quien destaca los aportes del investigador Mauricio Knobel, quien se ha comprometido con la investigación sobre la niñez y la adolescencia. Por consiguiente, resulta de interés y pertinencia ingresar a la dinámica del psiquismo a partir de una de las categorías teóricas de gran trascendencia que se propusieron en la investigación, como es la pulsión de muerte. De todas maneras, antes de avanzar con el texto, conviene hacer una breve explicación del concepto de pulsión, y para ello se acude a la presentación que hace Freud de este, como una "Representación psíquica de una fuente de excitación, continuamente corriente o intrasomática, a diferencia del "estímulo" producido por excitaciones aisladas procedentes del exterior. Pulsión es, pues, uno de los conceptos límites entre lo psíquico y lo físico" (Freud, 1981/1905, citado por Rosero, 2015, p. 135).

En la investigación, de la cual surge el presente artículo, se propuso como objetivo general la comprensión de la pulsión de muerte en los actos violentos presentes en un grupo de internos que han cometido homicidios que se encuentran recluidos en la Cárcel Judicial (INPEC - Pasto) Por las características de la investigación, cuya población 
son adultos que están bajo medida judicial de privación de la libertad, se parte de tres categorías de análisis: Acontecimiento, Repetición y Rectificación Subjetiva.

\section{Metodología}

La investigación asumió como referentes metodológicos el paradigma cualitativo, el enfoque hermenéutico y el tipo etnográfico, utilizando instrumentos de recolección de información tales como: historia de vida, entrevista semiestructurada y grupo focal. Con relación a la población participante en la investigación, se trata de internos de la cárcel judicial de Pasto, ubicados en los patios 3,4 y 7 , donde se hayan localizados, en su mayoría, población que ha cometido homicidio. Del total de internos de los patios en mención, se procedió a seleccionar una muestra de 46 participantes, que cumplieron con los criterios de selección: firma del consentimiento informado, tener condena por homicidio y cumplir con la edad establecida (entre 18 y 30 años).

Con respecto a los alcances metodológicos de la investigación, ésta se realizó en dos fases. La primera fase fue de carácter exploratorio, descriptivo y con sentido hermenéutico, apuntando a dar cuenta de los procesos psíquicos que soportan la dinámica de la pulsión de muerte, a la luz de las categorías previamente mencionadas. La segunda fase se apoyó en los resultados cualitativos y etnográficos que se desprendieron de la anterior fase, y con esto se realizó una propuesta de intervención denominada "Rectificación subjetiva: Compromiso con la No-Repetición y acontecimiento", orientada a los procesos de resocialización de los internos de la cárcel judicial de Pasto que hicieron parte de la investigación.

\section{Resultados}

\section{Reflexionando sobre el concepto de acontecimiento}

A partir de la realización de la investigación fue importante el desarrollo conceptual y epistemoló- gico de la categoría de acontecimiento $\mathrm{y}$, desde luego, logrando un complemento con la información recolectada a través de la aplicación de los instrumentos investigativos (historia de vida, entrevista semiestructurada y grupo focal) a la población de internos del contexto carcelario del INPEC de la ciudad de Pasto. Por consiguiente, según Deleuze (2005),

El acontecimiento está hecho de la cosa misma (lo que sucede) y de la impresión (a la vez espontánea y controlada) que tal cosa nos da, nos deja, nos hace [...]. Los acontecimientos son ideales. Novalis llega a decir que hay dos tipos de acontecimientos, ideales los unos, reales e imperfectos los otros; por ejemplo el protestantismo ideal y el luteranismo real. Pero la distinción no está entre dos clases de acontecimientos: está entre el acontecimiento, ideal por naturaleza, y su efectuación espaciotemporal en un estado de cosas. Entre el acontecimiento y el accidente. Los acontecimientos son singularidades ideales que se comunican en un solo y mismo acontecimiento; tienen además una verdad eterna, y su tiempo nunca es el presente que los efectúa y los hace existir, sino el Aión ilimitado, el Infinitivo en el que subsisten e insisten. Los acontecimientos son las únicas (p. 45).

Igualmente, es relevante hacer alusión a lo que manifiesta Deleuze (2005) con relación a la categoría de acontecimiento. La cuarta persona del singular es una de las expresiones con las que el autor (Deleuze, 2005, p. 78) denota el advenimiento del acontecimiento, es decir, de lo incalculable, pero que de todas maneras propicia cierta vivencia del pensamiento.

Pero bien, lo que da a entender es un direccionamiento de una existencia impersonal, libre de la subjetividad y la objetividad que sucede. Por lo tanto, esa vida, pre individual, pre subjetiva se puede asemejar con otra enunciación, la cual refleja una potencia irrepresentable: la muerte.

Desde esta perspectiva, es posible seguir a Deleuze (2005) con su reflexión sobre la muerte como acontecimiento: 
Como los dos aspectos de la muerte que Blanchot distinguía hace un momento: la muerte como acontecimiento, inseparable del pasado y del futuro en los que se divide, nunca presente, la muerte impersonal que es «lo inaprensible, lo que no puedo captar, que no está ligado a mí por ninguna relación, de ninguna clase, que nunca sucede, hacia la que no me dirijo»; y la muerte personal que sucede y se efectúa en el más duro presente, «que tiene como horizonte extremo la libertad de morir y el poder de arriesgarse mortalmente» (p. 113).

En algunos ecos que Blanchot deja acerca de la muerte, Deleuze (2005) indica un encuentro con el acontecimiento por antonomasia, al encontrar en ésta una paradoja fundamental que le permitirá decir que en todo acontecimiento hay un momento presente de la efectuación, en el que se encarna en el presente de las cosas materiales, y otro en el que solo puede ser considerado en sí mismo, no cósmico e intemporal. La muerte entonces se asume bajo la ambigüedad de que sucede en mí, de algo que me pasa en un momento determinado, es decir que acontece en un presente, pues siempre, al igual que todo acontecimiento será doble e impersonal.

Por lo anterior, se cree de suma importancia escuchar a las voces convocadas, cuando hacen alusión al concepto de muerte, catalogado como un acontecimiento: "Los sujetos participantes expresan que un acontecimiento significativo es la muerte de un ser querido, como se manifiesta en lo expresado por el sujeto No. 001-3: con la muerte de mi padre el mundo se me vino encima" (entrevista semi-estructurada).

En este sentido, la muerte se conceptualiza según Marcuse (1983), a partir de los referentes de la metapsicología freudiana, según la cual

Freud englobó estos aspectos en un principio dual: Eros y Tánatos. El primero es un instinto que comprende tanto los instintos sexuales como aquellas fuerzas sublimadas, originariamente instintivas, que han sido, por tanto, desviadas de sus fines, pero al servicio de la cultura (el arte sería el mejor ejemplo de esfuerzo sublimado). Tánatos subsumiría en su seno los instintos de destrucción, la relación entre ambos es la dialéctica: el Eros puede ser destructor con el fin de imponer sus condiciones y Tánatos aspira a la quietud última, la de la materia inorgánica, en la que la ausencia de placer es total, pero también lo es la de dolor. La civilización, según Freud, se ha creado mediante esta eterna lucha entre instintos de vida contra instintos de muerte (p.12).

Por lo tanto, la muerte se define como una pulsión de destrucción, concepto que, de alguna manera, se ve reflejado claramente en las respectivas proposiciones construidas a partir de los datos e información resultante de la fase empírica. Es decir, la categoría de muerte es entendida como sinónimo de destrucción. Esto significaría que Tánatos propende por la quietud última, en la cual, la ausencia de placer es total, pero igualmente lo es la de dolor. Esto lo podemos observar en aquellas personas que por alguna u otra circunstancia asumen pulsiones de destrucción, como por ejemplo quitarle la vida a otro ser humano. Igualmente, dentro de esta disertación sobre Pulsión de muerte y actos delictivos, es relevante hacer alusión a aquello que manifestara uno de los sujetos convocados, en relación a otro concepto como es la pobreza: los internos de la cárcel expresan que, "un episodio importante en sus vidas lo constituye la pobreza en la adolescencia" (tomado de la entrevista semi-estructurada).

Frente a lo cual, se observa que la pobreza se presenta como una de las causas importantes para la consumación de ciertos actos delictivos y que traigan como una consecuencia el tener que permanecer en centro reclusorio, pagando una sanción determinada por las autoridades competentes. Asistamos nuevamente a un encuentro con el sujeto 11: "Que nuestra familia hemos estado sin dinero ni para un pan, entonces mi familia se dedicó a la delincuencia y yo también participé con uno de ellos en acompañar a despegar para así poder comer y vestir por unos días, entonces la pobreza de mi casa influye" (tomado de entrevista semi-estructurada). 


\section{La dinámica de la repetición}

En el mundo penitenciario y carcelario se encuentran historias de vida que son producto de circunstancias que emergen en momentos cruciales en la vida de cada sujeto, que de una u otra manera se repiten y van a incidir en su proyecto de vida de forma significativa. Ahora bien, antes de continuar la exposición, es conveniente hacer una breve alusión al concepto de repetición, que Freud lo había reconocido desde sus reflexiones teóricas y clínicas, que se derivan del inevitable planteamiento de la pulsión de muerte. Si le seguimos la pista a lo que aquí se abre, tenemos que hacer al menos una alusión puntual al complejo y espinoso tema de la pulsión de muerte. Para tal efecto, se acude al escrito de Rosero (2015), quien afirma que

Su formulación, como el mismo Freud lo estima, obedece a una hipótesis que surge del campo de la clínica y a la vez de su aguda observación de las actuaciones humanas. Freud tendrá que reconocer que hay una compulsión a la repetición, la cual se halla "más allá del principio del placer", que a su vez está en la base de la pulsión de muerte. (p. 135)

Retomando la investigación, y ya con el concepto de repetición como base para el análisis, cabe mencionar que en los diferentes patios en los cuales se encuentran los internos dentro del contexto carcelario, se entrecruzan dinámicas complejas en las cuales circulan pensamientos, imágenes, emociones, sentimientos, producto de sus vivencias que experimentan en este lugar posibilitando en ellos evocar recuerdos de los actos que han cometido.

En ese sentido, al ubicar la repetición como un asunto que trae aparejado el componente del placer, resulta difícil que el discurso consciente de los internos reconozca su presencia y a la vez su determinación. De todas maneras, cuando se hizo la exploración sobre aquellos actos que atentan contra las leyes establecidas y que son realizados en forma frecuente, uno de los sujetos refiere que: "Hurtaba casi todos los días porque esa era la forma de vida mía, pero nunca con un propósito, siempre para rumba" (Entrevista semi-estruc- turada al sujeto No. 8, patio 4). El delito homicida es objeto de represión, y en su lugar aparecen más bien aquellos delitos considerados como menores, tal y como los delitos contra la normatividad de tránsito, que puede aflorar con mayor facilidad y a la vez cargados de una dosis especial de satisfacción; la negación sigue actuando como el mecanismo que protege contra la angustia y el sufrimiento humano: "No la verdad yo no llevo a cabo infracciones contra la ley. Bueno de pronto contra el tránsito" (Entrevista semi-estructurada al sujeto No. 10 , patio 4 ).

Con relación al concepto de repetición, Mesa (2010), parafraseando a Freud, afirma que

siempre se repite algo, y eso que se repite está en relación con algo no tramitado, con algo que se escapó en un momento dado y permanece perdido, con algo que obstaculiza el transcurrir de la vida anímica y merma la fibra del principio de placer. En este orden de ideas, Freud articula la repetición alrededor de un fracaso, se repite en tanto existe una deficiencia, un saldo que permanece sin abono, algo frente a lo cual el aparato anímico sólo puede reaccionar repitiendo (p. 10).

De lo anterior, se puede anotar que, en los sujetos entrevistados, los cuales han cometido homicidio y que lo han realizado varias veces, sienten de manera inconsciente el deseo de repetirlo como una tendencia para poder disfrutar del acto cometido, lo cual genera en ellos un comportamiento compulsivo que moviliza el deseo mismo de buscar disminuir la carencia, reduciendo de esta manera el monto de ansiedad. Sigue en este orden de ideas el profundizar la búsqueda en su estructura psíquica los motivos que empujan a estos individuos, y con esto analizar el mecanismo que posibilita esa repetición.

En los sujetos participantes en la investigación, se encuentra que, en varias ocasiones al cometer el acto delictivo se les escuchaba mencionar las preguntas del por qué cometieron el homicidio, lo que a su vez generaba una crisis existencial marcada que los conducía muchas veces al tedio y a la desesperanza; y más aún se presentaban 
dichos cuestionamientos si habían cometido dos o más homicidios a la vez, porque no lograban explicar qué les impulsaba a realizar dichos comportamientos.

Lo mencionado anteriormente emerge después de tomar conciencia de su historia personal, de sus relaciones sociales y de su encuentro con el otro en algún momento de sus vivencias; porque si hay algo cierto es que la crisis existencial surge en el momento de realizar una introspección la cual lleva a los sujetos a evocar esos momentos de dolor y de disfrute en otras ocasiones, pero que su vez los sumerge en una incertidumbre.

Cabe señalar que la repetición se genera como el acto en el cual el sujeto desea volver a experimentar cierto goce o satisfacción de lo que ha realizado anteriormente pues es el recuerdo lo que produce placer en cierta forma. Sin embargo, en los sujetos que han cometido delitos, queda el interrogante de qué es a aquello que los mueve a cometer actos delictivos y por qué se repiten, produciendo en ellos goce; este es un interrogante existencial que lleva a los sujetos a experimentar, en algunas ocasiones, sentimientos de culpa y que en muchas veces no tienen respuesta alguna a esta pregunta.

Es importante adentrarnos nuevamente al concepto de repetición, que según Álvarez (2016):

Un aspecto fundamental de explicitar es que con la primera teoría lacaniana de la repetición aparecía operando en el inconsciente una ley, que sin ambages podemos decir que determinaba la aparición de los significantes en la cadena simbólica. La repetición tomaba el carácter de una ley que operando en el inconsciente hace emerger al propio sujeto del inconsciente, un sujeto que se constituye en función de dicha ley (p. 247).

A partir de lo expuesto se puede analizar que la repetición se convierte en algo que el inconsciente no puede dejar de hacer; es un proceso que surge al consciente sin que exista barrera alguna que frene ese impulso, lo que hace que los sujetos actúen de forma automática sin medir las consecuencias de sus actos.
Revisando uno de los textos de Freud (1914), en el cual coloca el acento sobre la repetición, el autor manifiesta que

[...] el analizado repite en vez de recordar, y repite bajo las condiciones de la resistencia [...] Repite todo cuanto desde las fuentes de su reprimido ya se ha abierto paso hasta su ser manifiesto: sus inhibiciones y actitudes inviables, sus rasgos patológicos de carácter. $Y$ además, durante el trata miento repite todos sus síntomas (p. 153).

Es decir, que se puede analizar que los sujetos de la investigación tienen en su inconsciente ciertos deseos reprimidos, que hacen que en un momento de su vida ante un evento se desplacen a la esfera de lo consciente, propiciando que de esta manera actúen de manera impulsiva como ha ocurrido en el acto delictivo; es en este preciso instante en el cual se puede observar que este acto ocurre sin que se pueda hacer algo para evitar que esto suceda. El motivo que desencadena el acto que se repite se coloca en escena estrictamente para darle paso a una reacción que ya resultaba inevitable; no en vano, los internos refieren situaciones que rodean la ejecución del acto delictivo en términos de la cotidianidad de su vida, que a los ojos del simple observador pueden parecer como algo irrelevante, tal y como lo dice uno de los sujetos participantes en la investigación: "Estaba en mala situación económica. Me pagaban barato en el trabajo de albañilería y me dejé llevar por unos amigos" (entrevista realizada al sujeto No. 5 ).

Con lo anterior, para los propósitos del estudio resultó importante analizar el concepto de repetición, puesto que el mismo posibilita acceder a lo más profundo de la psiquis de los sujetos que fueron objeto de la investigación, y esto a su vez posibilita comprender cuáles son los mecanismos que operan para que un acto se vuelva a repetir; siendo necesario aclarar que es importante tener en cuenta que en la vida de estos sujetos se presentan acontecimientos los cuales han incido de una u otra manera en los delitos que han cometido. Resulta necesario ahora hilar el texto con otro de los ejes que permiten comprender el psiquismo 
de un sujeto que ha cometido un delito como el homicidio, y para tal efecto se procede a la disertación en función de su responsabilidad.

\section{Responsabilidad subjetiva: aportes a la construcción del tejido social}

Uno de los asuntos que más resalta en la investigación es la dificultad que se observa en los participantes para que asuman la responsabilidad con sus actos, entendido el acto como aquel que proviene de su propia subjetividad, que tiene una perspectiva absolutamente ética, esto es, que lo implica al sujeto en su condición única e irrepetible, y con esto de una ética que conlleva un asunto de gran profundidad como es la responsabilidad. Esta premisa es la que se observa en uno de los sujetos participantes en la investigación, al afirmar en la entrevista semi-estructurada: "Los errores uno los comete de un rato para otro. Yo no fui con el pensamiento de matar a alguien. Nunca he pensado en matar" (sujeto No. 5 del patio 4).

En ese sentido, esta disertación conlleva anudar varios conceptos como son ética, salud mental, lazo social y derecho; entendiendo, a partir del último referente, que interesa también el tema del castigo y la culpa. Y de tal complejo de conceptos, emerge uno de ellos que se convierte en el centro de la presente reflexión, en el sentido que hay un referente que les cuesta mucho trabajo asumir a las personas que han llevado a cabo un acto delictivo, y que se ubica en términos de su responsabilidad, esto es, de reconocer en su comisión su propia decisión, una elección personal que ha pasado por los finos procesos inconscientes hasta llegar a la superficie de la conciencia.

Con el fin de referenciar esta condición, se presentan algunos testimonios en los cuales se percibe la posición de los internos frente a la comisión de una acto delictivo: en la entrevista semi-estructurada uno de los sujetos afirma que "Actúo normalmente, porque yo no he hecho nada malo" (sujeto 4 del patio 3), o una posición mucho más radical y hasta camaleónica en otro de los sujetos quien afirma que "Cuando cometo una falta contra la ley, escapo, me escondo, me disfrazo y me cuido de no caer a un CAI ni a una URI" (sujeto 11 del patio 3).

En concordancia con lo anterior, se acude a uno de los conceptos formulados por el psicoanálisis, que procede de la clínica analítica (inaugurada por Freud) y que fue apartado por el psicoanalista francés Jacques Lacan: la rectificación subjetiva. Este concepto se halla en la base de la responsabilidad (también subjetiva), y por eso vale la pena buscar sus orígenes y delimitar sus alcances. La revisión que se ha hecho del concepto indica que su primera aparición está en la obra de Lacan (1981) "La dirección de la cura y los principios de su poder", incluida en los Escritos 1 (1981), donde el autor afirma que la rectificación subjetiva se considera como aquel eslabón fundamental para el ingreso en análisis, tal como Miller (2013) lo establece al afirmar que es

Algo que acompaña o condiciona la verdadera entrada en análisis, algo que es el primer momento de esa entrada. El ejemplo es del caso Dora: ella se acerca al análisis quejándose de los demás; la culpa es de mi padre..., la culpa es de ese hombre que me persigue..., la culpa es de esa mujer que no se preocupa de mí...; Dora, antes de entrar verdaderamente en análisis, debe percibir que todo eso tiene que ver con su responsabilidad (Párrafo 6).

Como se puede observar, si bien el concepto de rectificación subjetiva presentado por Miller (2013) tiene una procedencia de la clínica, tomado de la experiencia que ocurre con el paciente, quien tendrá que elaborar o darle un nuevo sentido a la queja con la que llega a su análisis. Con relación a esta situación tan particular, más adelante Miller (2013) afirma:

Hay un primer tiempo donde el sujeto que entra en análisis para quejarse de los demás debe percibir su responsabilidad subjetiva personal. Es decir, percibir que de lo que tú te quejas, es tu propia culpa. Esto resulta sorprendente si se piensa que el psicoanálisis es el aprendizaje de la exculpación. ¡Es mi inconsciente! yo no soy responsable de nada... 
Al contrario: lo que uno aprende en análisis, si aprende algo, es que es responsable de todo lo que le ocurre. Así, para decirlo de una manera un poco dramatizada, el sujeto del inconsciente es siempre un acusado. $Y$ por eso es tan importante en la teoría analítica el concepto de superyó que significa precisamente es: que, en el nivel más profundo, el sujeto es un acusado (Párrafo 6).

El cambio que se traduce en la sentencia de Miller es la de un sujeto que ha dejado de quejarse o atribuir culpas a los otros de sus propias decisiones o atolladeros, para ahora dirigir la responsabilidad de sus actos en sí mismo.

Como nos damos cuenta, el asunto de la rectificación subjetiva tiene una gran trascendencia en el trabajo que se lleva a cabo en aquellas instituciones llamadas a adelantar procesos de rehabilitación social, lo cual, en última instancia, conlleva un ejercicio de gran envergadura, como es colocar al sujeto infractor o contraventor no solo frente a sí mismo sino sobre todo frente al lazo social, a las relaciones que establece con el otro, con las normas que se han tejido para regular tal relación. Este ejercicio es de gran trascendencia en sujetos como los internos en una cárcel, quienes tienen la oportunidad de resignificar el sentido de su vida a partir de su experiencia como internos en un establecimiento penitenciario, tal y como lo afirma uno de los sujetos participantes en la investigación: "Yo nunca he actuado de esa manera sino cuando me cogieron para el ejército. Ha sido una experiencia muy desagradable y me siento muy mal" (Entrevista semi-estructurada, sujeto $15 \mathrm{del}$ patio 4).

Está de por medio aquí una consideración que muestra a todas luces una perspectiva del sujeto, según la cual, si bien es cierto la lógica de la ciencia, de la justicia y del lazo social, es establecer causalidades y determinaciones imposibles de evitar, el sujeto que comete un acto delictivo asume una posición de resistencia ante tal principio. Por esto, en instituciones como las de tipo carcelario, donde se hallan internos sujetos acusados de haber cometido un acto que vulnera la legalidad de una nación, se escuchan las voces de sujetos que no asumen su responsabilidad, no se ubican en el paradigma según el cual todo tiene una razón y una causa. Sujetos que no se sienten y no se asumen como efectivamente responsables de lo que han hecho. Sujetos que en la entrevista semiestructurada, se presentan con el rostro de la negación, negando toda suerte de responsabilidad en el acto delictivo cometido: "Ahora, he aprendido a valorar a mis padres y a los que me rodean. No he hecho nada" (Entrevista semi-estructurada, sujeto No. 13 del patio 4).

La tarea, entonces, que aparece en el horizonte es en términos de la rectificación; lo cual, dicho sea de paso, no resulta nada fácil. Como ya se ha dicho, que se pase de una queja en la cual la culpa y la responsabilidad se descarga en sus padres que los abandonaron; su madre que no lo cuidó cuando era niño; o de un Dios que ha sido supremamente despiadado con ellos; del gobierno que no ha atendido sus necesidades e incluso de la suerte que les ha fallado desde siempre, a un lugar donde ésta población asume la responsabilidad con sus propios actos, al precio también de emprender un camino que es el más conveniente en estos casos, que es el de la reparación.

Palabras de los internos de la cárcel judicial de Pasto, quienes luego de un tiempo que llevan de reclusión, reconsideran su posición ante la vida, ante sí mismos y ante el otro, como se evidencia en los siguientes testimonios tomados de la entrevista semi-estructurada: "Sí, lo he prometido, no repetirlo y lo he tratado de cumplir" (sujeto No. 3 de patio 3), "Sí, antes no pensaba en la consecuencia de los actos, ahora pienso antes de actuar, he aprendido que toda acción tiene consecuencia" (sujeto No. 12 del patio 3).

El trabajo con la población de internos implica pasar de un ejercicio que los recubre de lástima y paternalismo, a un proceso que conlleve lo que autores como Zawady (2005) proponen en términos de la responsabilidad subjetiva. Un movimiento que implica un trabajo efectivamente formativo, en el sentido de colocar al sujeto como un sujeto efectivamente responsable de sus actos, donde la dimensión de lo inconsciente no le sirve de justificación para el acto delictivo cometido, 
sino todo lo contrario, para asumir en toda su potencia lo que significa ser un sujeto de derechos, con las obligaciones que ello trae consigo.

Responsabilidad subjetiva y reparación pueden plantearse como dos caras de la misma moneda, donde la primera se convierte en el acicate para que ocurra la segunda, permitiendo de esta manera la resignificación de la existencia y su posición en el mundo. Por esto, conviene afirmar que el asunto de la reparación es de gran importancia con la población carcelaria, y en gran medida ha generado algunas evidencias de su ejercicio, al punto que cuando a los internos se les pregunta sobre los cambios que han ocurrido en su vida luego de su ingreso a la cárcel, responde uno de ellos en la entrevista: "No sé porque estoy preso, pero de mi niñez hasta mis 18 años si ha cambiado, ahora tengo 26 años, pero 3 años perdidos aquí. Entonces, cambio total en este último año, que me doy cuenta que quiero un futuro mejor, con una buena mujer y un hijo que quisiera tener en la calle cuando salga. Dejar la delincuencia" (sujeto No. 11 del patio 3).

Hoy se entiende, entonces, que la perspectiva en función del lazo social requiere todo un trabajo analítico e interventivo de gran intensidad. La construcción de un tejido social en el cual todos los sujetos de una región o una nación generen o permitan las condiciones que permitan escuchar a aquellos sujetos que han llegado a cometer un acto delictivo, a quienes no se les ha permitido el soberano ejercicio de su palabra, de expresarse en un discurso que tiene mucho que decir sobre su vida, sobre sus relaciones con el otro, y en particular de las voces que provienen del Otro, en su dimensión superyóica.

Estas líneas pretenden hacer una invitación a trabajar con el sujeto que se halla en un establecimiento penitenciaria o en cualquier contexto de rehabilitación en una perspectiva que vaya más allá de la medida punitiva y judicial, abriéndose paso un trabajo que se denomina de intervención psicosocial, que se oxigena con los aportes que se pueden tomar de la psicología y el psicoanálisis en función de la rectificación subjetiva, la responsabilidad subjetiva y la reparación.

\section{Discusión}

La investigación representa el escenario privilegiado para acceder, de manera idónea, a la esfera personal de un grupo de internos de la cárcel judicial de Pasto, y analizar a través de la propuesta de intervención desarrollada la información sobre las categorías tales como acontecimiento, la repetición y la rectificación subjetiva, tomando en cuenta cada una de las vivencias de sus protagonistas.

Con relación al acontecimiento, se tomó la perspectiva de Foucault (1974), quien lo ubica en los términos de aquellos eventos que se convierten en hitos en la historia del sujeto, que rompen con la continuidad de los eventos de la vida y muestran de esta manera los cortes que reorganizan la historia de su vida. Acontecimientos que, como la muerte, se ubican en el territorio de lo inexpugnable para el sujeto, en tanto pertenecen al orden de lo real.

En el caso de los internos de la cárcel judicial de Pasto, la exploración que se hizo con ellos sobre sus vidas permitió dar cuenta de asuntos que, como la pobreza, la muerte de un familiar cercano, se hallan registrados en su estructura psíquica y desde allí producen efectos en sus emociones, sus pensamientos y los actos que llevan a cabo. Acontecimientos que, de una u otra manera, y al no tener otra vía de elaboración o trámite por las vías psíquicas que existen para tal efecto (con la consiguiente reconstrucción de los significados de las experiencias vividas en el pasado), tienen una oportunidad de expresión en el presente y en el caso presente en forma de conductas delictivas por las cuales llegaron al establecimiento penitenciario.

Se observa la acción y presencia de uno de los principios que caracterizan al psiquismo, como es la repetición, la cual se regula según las leyes de lo inconsciente. Este principio permite evidenciar que el comportamiento de las personas que cometen un acto delictivo tiende a su repetición, que los hechos del pasado tienden a retornar al presente, en una suerte de retorno de lo reprimido o de eterno retorno, hasta tanto no reciba la re-elaboración para así darle el cauce que se merecen 
en un contexto de interacción y convivencia con el otro. Lo anterior permite comprender cómo la emoción que conlleva la muerte de un ser querido todavía marca la experiencia cotidiana de los internos, y es por esto por lo que la tristeza, la angustia y la desesperanza brotan con gran facilidad en cualquier momento de su vida. Por lo demás, este afecto toma un matiz bastante especial en las narraciones de los internos, quienes relatan que cuando cometieron un delito (sobre todo el de homicidio) su realización traía consigo una carga de placer, que finalmente determina su nueva repetición.

A partir de estas reflexiones, que tocan los núcleos de la subjetividad, la investigación abrió el lente para observar otro de los asuntos al cual debe desembocarse cuando se trabaja con los internos de una cárcel: algunos lo llaman responsabilidad, y con justa razón. No obstante, en el marco conceptual se prefirió tomar el camino de la rectificación subjetiva, en tanto representa el orden en el cual el sujeto asume su propio lugar ante la comisión de un acto cualquiera que sea, y al cual muchas veces se pretende esquivar bajo el principio de la suerte, la indeterminación o el destino.

Los sujetos participantes en la investigación reconocieron que el acto homicida o delictivo en general, si bien es cierto representa una cuota de placer para quien lo ejecuta (según los designios de la repetición ya comentada), también es cierto que deja asomar el sentido de la culpa, y con esto calificar que lo hecho puede catalogarse como algo "malo", que fue una "equivocación", por el daño causado a la víctima y sus familias.

El trabajo investigativo a partir de la categoría de rectificación subjetiva, y con esta de su aliado que es la responsabilidad subjetiva, muestra en algunos apartes a estos seres a quienes la privación de la libertad les brinda la posibilidad de asumir con ética el acto cometido. $Y$ gracias a ello, hoy se colocan, así sea imaginariamente o gracias a la evocación, frente a frente con la muerte de otro, llámese conciudadano, vecino o contrincante fruto de las divergencias de la vida, y sienten el peso de una conciencia moral que produce sus efectos sobre el sujeto. Es el sujeto-interno, condenado por un delito, quien, en el silencio de su soledad, sin la mirada de otro que lo juzgue y determine, ha tomado la decisión de asumir una postura ante la vida, más allá de la benevolencia de unos u otros, sino que reconoce el valor de los códigos sociales que dignifican la existencia y descalifican todo acto atroz que cauce la muerte. Rectificación subjetiva que trajo a escena algunas de las expresiones del superyó como son el dolor, el remordimiento y el arrepentimiento.

La rectificación subjetiva, la repetición y los acontecimientos fueron las tres categorías que, de manera hilada, fueron revelando el tejido humano (demasiado humano, como lo diría Nietzsche) de un sujeto que ha cometido un acto delictivo, presa de la ferocidad de la pulsión de muerte, pero que ahora tiene la oportunidad de revelar los sentimientos, emociones y pensamientos que se hallan ocultos en la estructura inconsciente de su constitución psíquica.

Y vale la pena cerrar esta discusión con la palabra de algunos internos participantes en la investigación, quienes han elegido como opción de vida la decisión de no lo vuelvo a hacer, esto es, que no volverán a cometer el delito por el cual se hallan en la cárcel.

\section{Conclusiones}

En este apartado se presentan deducciones relevantes con relación a las categorías trabajadas en la investigación Pulsión de muerte y actos delictivos.

En este sentido, la noción de acontecimiento es entendida como una vivencia del sujeto, llena de situaciones y circunstancias relevantes que, de alguna manera, dejan huella en él, y hacen que éste recuerde dicha experiencia. El acontecimiento se comprende algunas veces, desde el placer y otras desde el displacer, pero desde luego, con una fuerte influencia en los comportamientos y pensamientos del sujeto.

Es así como el individuo que a partir de los acontecimientos y sucesos vividos y, que por supuesto, 
lo han marcado, llegará a enmarcar todas esas experiencias dentro de su quehacer cotidiano.

Ahora bien, para efectos de la presente reflexión, es importante ubicar que el asunto de la rectificación subjetiva proviene del campo de la clínica psicoanalítica, como un horizonte en el cual el sujeto asume la responsabilidad de sus actos. Esto es, deja de asumir que la suerte o el destino de su vida no recae estrictamente en las acciones u omisiones de los demás, y en particular de las figuras más significativas en su vida, como son sus padres o las figuras de identificación que van apareciendo en su historia personal.

Si se vuelve sobre las palabras de los sujetos participantes en la investigación, hay una expresión que toma cuerpo como significante: "no lo vuelvo a hacer". Palabras que concentran en su interior el valor social y ético de la rectificación subjetiva. Claro, será en el lazo social donde esta expresión tendrá su real dimensión, y con mayor precisión en las manifestaciones sociales de la pulsión de muerte, como un hecho que supera las coordenadas del psiquismo personal hasta trascender a las tensiones que se producen en los encuentros propios de la intersubjetividad. La pulsión de muerte entonces, no se queda en los terrenos del sujeto en su condición singular, llegando a producir fracturas en las relaciones que se producen en el encuentro agresivo / violento con el otro.

Por otro lado, la rectificación toma para sí otro aliado estratégico, que es la repetición, o más bien la negación de esta. Los internos de la cárcel judicial de Pasto, sujetos que están en este establecimiento penitenciario para purgar una condena social por un acto cometido de tipo antisocial, plantean que están dispuestos a asumir un compromiso de no-repetición, siendo esto algo que para muchos es solo una ilusión o una fantasía que no merece mayor grado de validez y reconocimiento.

Con relación a la repetición, se concluye que a partir de las experiencias vividas los sujetos investigados recuerdan en varias ocasiones el acto del homicidio cometido, el cual dejó una huella mnémica que se inscribe en lo más profundo de su aparato psíquico. Si repetir es recordar, daría lugar entonces de cierta manera a que los sujetos que han cometido varios homicidios recuerdan el evento con placer debido al goce que les produjo los homicidios cometidos. Sin embargo, habría que repensar hasta qué punto el placer de matar se convierte en algo gratificante en la vida de estos sujetos puesto que están inmersos en el consumo de sustancias psicoactivas, y otros delitos como el robo, al igual que conductas antisociales lo cual que de una u otra forma incide en su comportamientos individual y social.

\section{Referencias}

Álvarez, M. (2016). La repetición, una interpretación psicoanalítica: Freud y Lacan. Madrid: Universidad Complutense De Madrid.

Deleuze, G. (2005). Lógica del sentido. Barcelona: Paidós.

Foucault, M. (1974). La hermenéutica del sujeto. México: Siglo XXI.

Freud, S. (1991). Recordar, repetir y elaborar (Texto original publicado en 1914). Buenos Aires: Amorrortu.

Marcuse, H. (1983). Eros y civilización. Madrid: Sarpe.

Lacan, J. (1981). Escritos 1. México: Siglo XXI Editores.

Mesa, D. (2010). La repetición bajo dos puntos de fuga: el psicoanálisis y la filosofía. Revista Cuadrante Phi, 21, Julio - diciembre de 2010, Bogotá, Colombia, pp. 1-20. Recuperado: http://www.javeriana.edu.co/cuadrantephi/ pdfs/N.21/2.pdf

Miller, J. (1998). Introducción al método psicoanalítico. Buenos Aires: Paidós SAICF.

Miller, J. (2013). Rectificación subjetiva. En: https:// centrohernandez.wordpress.com/2013/03/08/ rectificacion-subjetiva-j-a-miller/ 
Rosero, L. (2015). Transferencia y pulsión: ejes de la clínica analítica. Revista Affectio Societatis, 12(22), 128-139.

Sánchez, M. (2008). La repetición: un problema fundamental en el pensamiento de Kierkegaard. Revista Logos,13, 81-87.
Zawady, M. (2005). La responsabilidad subjetiva. Actualidad del planteamiento freudiano. Revista Desde el jardín de Freud, 5, 128-143. 